\title{
KNOWLEDGE AS A PREDICTOR OF HYPERTENSION PREVENTION PRACTICES AMONG SECONDARY SCHOOL TEACHERS IN A SELECTED LOCAL GOVERNMENT AREA IN OYO STATE, NIGERIA
}

\author{
Oyelade Blessing Olaoluwa ${ }^{1}$ and Ademola Amosu ${ }^{2}$ \\ ${ }^{1}$ Department of Public Health, School of Public and Allied Health Babcock University, \\ Ilishan-Remo Ogun State, Nigeria. Email: olablessing80@ gmail.com \\ ${ }^{2}$ Department of Public Health, School of Public and Allied Health Babcock University, \\ Ilishan-Remo Ogun State, Nigeria.
}

Cite this article:

Oyelade B.O., Ademola A. (2021), Knowledge as A Predictor of Hypertension Prevention Practices Among Secondary School Teachers in a Selected Local Government Area in Oyo State, Nigeria. International Journal of Public Health and Pharmacology 1(1), 62-73. DOI: 10.52589/IJPHP-P2V1L0J9.

\section{Manuscript History}

Received: 5 May 2021

Accepted: 5 June 2021

Published: 20 June 2021

Copyright $\odot 2020$ The Author(s). This is an Open Access article distributed under the terms of Creative Commons AttributionNonCommercial-NoDerivatives 4.0 International (CC BY-NC-ND 4.0 ), which permits anyone to share, use, reproduce and redistribute in any medium, provided the original author and source are credited.
ABSTRACT: Globally, hypertension remains one of the most pressing public health challenges. Therefore, this study investigated knowledge as a predictor of hypertension prevention practices among secondary school teachers in Ogbomoso North Local Government in Nigeria. The research adopted a crosssectional survey design. 418 public secondary school teachers in Ogbomoso North, Oyo State, were selected through a multistage sampling technique. A validated questionnaire was used for data collection. Statistical Package for Social Sciences (SPSS), version 23, was used at a 95\% confidence interval. The results showed that almost half of the teachers, 184 (47.8\%) were between the ages of 40 and 49 years with mean $\pm S D$ of 42.64 \pm 7.779 years. Majority of the teachers (96.1\%) knew that hypertension is caused by high blood pressure and early detection through regular monitoring is important. The risk factors were rightly identified by over half of the teachers. The level of knowledge was computed on a 21-point rating scale with mean $\pm S D$ of $14.79 \pm 2.298$. The level of preventive measures was moderate with a mean $\pm S D$ of $15.34 \pm 4.983$ on a 24-point rating scale. Knowledge had a significant but weak statistical relationship with practice of hypertension preventive measures $\left(R^{2}=0.040 ; p<0.01\right)$. The findings of the study suggest that there are gaps in knowledge regarding hypertension among teachers in Oyo State, which could influence their behaviours towards prevention. There is a need for comprehensive health education for this group of teachers.

KEYWORDS: Hypertension, Knowledge, Predictor, Prevention Practices, Teachers. 


\section{INTRODUCTION}

Hypertension is one of the most pressing public health challenges (Dzau \& Balatbat, 2019). Hypertension is one of the risk factors for cardiovascular diseases, and it is indirectly the leading cause of death and the third cause of disability globally (Chruściel et al., 2019). According to the World Health Organization, an estimated 1.13 billion people have hypertension globally. Hypertension is referred to as a silent killer in which the person who has it may not be aware and would neither show symptoms of having it (WHO, 2019). Hypertension or high blood pressure leads to 7.5 million death cases, which shares about $12.8 \%$ of all death cases recorded globally (Eman, 2020). The prevalence of hypertension remains considerably high globally, particularly in low and middle-income countries, despite the fact that hypertension can be prevented and controlled (WHO, 2019).

The development of chronic illnesses such as hypertension among individuals in occupations such as teaching has been associated with high levels of stress and sedentary behaviours (Mohan et al., 2008). Teaching is a profession that requires long working hours and teachers represent one of the most important, largest and productive sectors as they deliver cognitive knowledge to students. In Nigeria, teachers constitute part of the productive and elite sector in many communities. The work of school teachers includes interaction with people whose safety and well-being they are responsible for, apart from their role of teaching (Singh \& Singh, 2006). In addition to this, nowadays, teachers seem to be involved in other non-academic duties such as census enumeration and elections, and together, all these contribute to stress, which is a risk factor for hypertension (Monica et al., 2017).

An individual's practice of hypertension prevention is influenced by certain factors, which include psychological, cognitive, and social factors, among other factors which all together act to determine if the individual exhibits a preventive health behaviour or not. It is almost impossible to act on what you lack information about. When knowledge about a health condition is lacking, preventing the occurrence of such a condition would be difficult. This is consistent with what Adkins (2006) posited, that gaps in knowledge of cardiovascular conditions and their risk factors in the general population are important barriers in the effective prevention and treatment of cardiovascular diseases (Adkins, 2006). Gaps in knowledge of cardiovascular disease conditions and their risk factors serve as barriers in the effective prevention and treatment (Boateng et al., 2017). Changes in lifestyle variables, along with other non-pharmacological interventions, may play an important role in halting the increasing trend of the prevalence of hypertension in low and middle-income countries, where there is a scarcity of programmes for the prevention and control of high blood pressure (Lemogoum, 2014).

\section{LITERATURE}

In Southwestern Nigeria, prevalence of hypertension was estimated to be 55.5\% among semiurban residents (Olamoyegun et al., 2016). Babatunde et al. (2020) carried out a study on cardiovascular risk factors in the civil service of Oyo State, Southwestern Nigeria. The study, which made use of six selected local government areas of Oyo State, reported that the prevalence of cardiovascular risk factors was high, compared with other studies in Nigeria and Africa (Babatunde et al., 2020). In a study on the prevalence of obesity and hypertension among adults in Ogbomoso, Nigeria by Isaac et al., 2011, the findings revealed that the prevalence of 
hypertension among the study population was $50.5 \%$. Among the study population of this research were teachers, who were classified under the class 2 as intermediate (Isaac et al., 2011). The above established the prevalence of hypertension in the study area.

A study conducted in Ekiti, Southwestern Nigeria, reported that $100 \%$ awareness of hypertension among teachers, did not automatically translate to adequate knowledge of hypertension (Fasoro, 2017). Although several studies have examined the relationship between knowledge and prevention practices relating to hypertension, the majority of these studies made use of populations that were hypertensive. This study was premised upon the practice of lifestyle/behavioural factors that are applicable to all levels of hypertension prevention, be it primordial, primary or secondary prevention, among both healthy and hypertensive teachers. Also, there is sparse literature on the relationship between knowledge and prevention practices relating to hypertension among teachers in Ogbomoso, Oyo State. Thus, this research examined how knowledge could be used to predict the practice of hypertension prevention among teachers in Ogbomoso North Local Government Area. The research hypothesis states that there is a significant relationship between knowledge of hypertension and hypertension prevention practices among secondary school teachers in Ogbomoso North Local Government Area.

Following certain theoretical premises from the Health Belief Model (HBM), this research was developed.

\section{METHODOLOGY}

The study was conducted at Ogbomoso where Ogbomoso North Local Government Area is situated in Oyo State, Nigeria. The estimated total population of the LGA is 259,662, going by the 2006 census figure. The population for the study consisted of all public secondary school teachers in Ogbomoso North Local Government area of Oyo state, Nigeria. Data were collected within a period of three weeks. The study adopted a cross-sectional design. A prevalence of hypertension of 55\% (Olamoyegun et al., 2016), standard normal deviation of 1.96 and degree of precision of $95 \%$ were used in the sample size formula for the cross-sectional study. A sample size of 380 was calculated. However, 418 participants were recruited for the study so as to compensate for non-response by the participants. Ogbomoso North consists of 15 public secondary schools. The sampling technique used was the multistage sampling technique. The first stage made use of proportionate sampling to determine the numbers of teachers from each school who would participate in the study, while the second stage made use of purposive sampling method to select the calculated proportionate number of teachers from each school who would participate in the study. Participants eligible for the study were principals, vice principals, teachers in public secondary schools in Ogbomoso North Local Government Area. Participants excluded from the study were Corp members, teaching-practice students and nonteaching staff in public secondary schools in Ogbomoso North Local Government Area. Also, all private secondary schools were excluded from the study.

A self-administered questionnaire was used for data collection. In order to validate the questionnaire, a pilot study was carried out among 38 secondary school teachers in IlishanRemo, Ogun state, Nigeria, who had the same characteristics with our study population. The Cronbach's alpha reliability coefficient of the questionnaire was 0.711 for knowledge items 
and 0.865 for items on preventive practices. Ethical approval for the study was granted by the Institution Review Board of Babcock University (NHREC/24/01/2020; BUHREC 183/21). All teachers, who gave their informed consent and agreed to sign their informed consent, participated in the study. Data collected were processed and analysed using Statistical Package for the Social Sciences (version 23). Descriptive and inferential statistics were used in the analysis of the data.

\section{RESULTS}

The results for the study are shown in Table I to IV. The tables reflect the descriptive statistics on socio-demographic data, knowledge on hypertension and hypertension prevention practices among teachers. Descriptive statistics for the socio-demographic variables are shown in Table I.

\section{Sociodemographic Characteristics of Respondents}

The distribution of the teachers according to age showed that only $23(6 \%)$ were within the age group, 20-29 years, while almost half of the teachers $(184 ; 47.8 \%)$ were between the ages of 40 and 49 years. The mean age of the teachers was $42.64 \pm 7.779$ years (see Table I). The gender distribution of the teachers showed that 155 (40.3\%) were males while 230 (59.7\%) were females. The academic qualifications of the teachers were the National Certificate in Education $(54 ; 14 \%)$, Bachelor's degree $(289 ; 75.1 \%)$ and Postgraduate degree $(42 ; 10.9 \%)$. The teachers' work experience distribution showed that only 46 teachers $(11.9 \%)$ had experience of 1 to 5 years, 93 teachers $(24.2 \%)$ had experience of 16-20 years, while $62(16.1 \%)$ teachers had worked for over 20 years as teachers. Majority of the teachers $(347 ; 90.1 \%)$ were married, 6 $(1.6 \%)$ were widowed and $28(7.3 \%)$ were single. The religious distribution within the sample showed that about three-quarter of the teachers $(288 ; 74.8 \%)$ were Christians, $86(22.3 \%)$ were Muslims and 11 teachers $(2.9 \%)$ indicated other religions.

Table I: Sociodemographic Characteristics of Respondents

\begin{tabular}{|c|l|c|c|}
\hline S/N & Variables & Frequency $(\mathbf{N})$ & Percentage (\%) \\
\hline 1 & Age & & \\
& $20-29$ years & 23 & 6.0 \\
& $30-39$ years & 95 & 24.7 \\
& $40-49$ years & 184 & 47.8 \\
& $50-59$ years & 83 & 21.5 \\
& Total & $\mathbf{3 8 5}$ & $\mathbf{1 0 0}$ \\
\hline & Mean \pm SD & $\mathbf{4 2 . 6 4} \pm \mathbf{7 . 7 7 9}$ years \\
\hline \multirow{2}{*}{2} & Gender & 155 & 40.3 \\
& Male & 230 & 59.7 \\
& Female & $\mathbf{3 8 5}$ & $\mathbf{1 0 0}$ \\
\hline 3 & Total & 54 & 14.0 \\
& Academic Qualification & 289 & 75.1 \\
& NCE & 42 & 10.9 \\
& Bachelor's Degree & $\mathbf{3 8 5}$ & $\mathbf{1 0 0}$ \\
\hline
\end{tabular}




\begin{tabular}{|c|l|c|c|}
\hline 4 & Work Experience & 46 & 11.9 \\
& $1-5$ years & 99 & 25.7 \\
& $6-10$ years & 85 & 22.1 \\
& $11-15$ years & 93 & 24.2 \\
& $16-20$ years & 62 & 16.1 \\
\hline & $>$ 20 years & $\mathbf{3 8 5}$ & $\mathbf{1 0 0}$ \\
\hline 5 & Total & & \\
& Marital Status & 28 & 7.3 \\
& Single & 347 & 90.1 \\
& Married & 6 & 1.6 \\
& Widowed & 4 & 1.0 \\
\hline & Divorced & $\mathbf{3 8 5}$ & $\mathbf{1 0 0}$ \\
\hline & Total & 288 & 74.8 \\
\hline & Religion & 11 & 22.3 \\
\hline & Christianity & $\mathbf{3 8 5}$ & $\mathbf{1 0 0}$ \\
\hline & Islam & \multicolumn{2}{|c|}{} \\
\hline
\end{tabular}

\section{Knowledge of Teachers Regarding Hypertension}

Tables II and III present the descriptive statistics for the variables of participants' knowledge on hypertension. Majority of the teachers $(370 ; 96.1 \%)$ knew that hypertension is caused by high blood pressure and $326(84.7 \%)$ teachers stated that hypertension can be detected when the systolic blood pressure is greater than or equal to $140 \mathrm{mmHg}$. Regarding the knowledge of the teachers on the causes, $304(79 \%)$ rightly identified that having too many things on one's mind is a risk factor for hypertension, while $81(21 \%)$ had no knowledge of that. Majority of the teachers $(321 ; 83.4 \%)$ had knowledge regarding early detection through regular monitoring of blood pressure. One of the symptoms of hypertension - irregular heart rhythms - was rightly identified by $318(62.6 \%)$ teachers, while $372(96.6 \%)$ teachers knew that an uncontrolled hypertension can lead to stroke. About two-thirds of the teachers $(266 ; 69.1 \%)$ in this study asserted that the vision of people who have hypertension is usually poor. Measuring blood pressure was indicated by $322(75.8 \%)$ teachers as a detection method and $292(75.8 \%)$ stated that noticing strange feelings in the body can be a symptom of hypertension (see Table II). The distribution of the teachers' responses to the risk factors showed that $252(65.5 \%)$ knew that foods high in fats can cause hypertension. Also identified as risk factors are excessive salt consumption $(312 ; 81 \%)$, lack of exercise or physical activities $(292 ; 75.8 \%)$, taking too much alcohol $(284 ; 73.8 \%)$ and family history $(312 ; 81 \%)$ (see Table III). 
Table II: Distribution of the Knowledge of Teachers Regarding Hypertension

\begin{tabular}{|c|c|c|c|}
\hline$S /$ & ITEMS & $\begin{array}{c}Y E S \\
N(\%)\end{array}$ & $\begin{array}{c}N O \\
N(\%)\end{array}$ \\
\hline 1 & $\begin{array}{l}\text { Hypertension is caused by too high blood pressure } \\
\text { in the blood vessels of the body }\end{array}$ & $370(96.1)$ & $15(3.9)$ \\
\hline 2 & $\begin{array}{l}\text { Hypertension is systolic blood pressure greater than } \\
\text { or equal to } 140 \mathrm{mmHg} \text {, or diastolic blood pressure } \\
\text { greater than or equal to } 90 \mathrm{mmHg}\end{array}$ & $326(84.7)$ & $59(15.3)$ \\
\hline 3 & $\begin{array}{l}\text { Hypertension is caused by having many things on } \\
\text { your mind }\end{array}$ & $304(79.0)$ & $81(21.0)$ \\
\hline 4 & $\begin{array}{l}\text { Regular monitoring of blood pressure can make } \\
\text { one diagnose hypertension early }\end{array}$ & $321(83.4)$ & $64(16.6)$ \\
\hline & The nature of hypertension & $\begin{array}{l}\text { YES } \\
\mathbf{N}(\%)\end{array}$ & $\begin{array}{l}\text { NO } \\
\mathbf{N}(\%)\end{array}$ \\
\hline 5 & $\begin{array}{l}\text { Hypertension produces irregular heart rhythms as } \\
\text { an important symptom }\end{array}$ & $318(82.6)$ & $67(17.4)$ \\
\hline 6 & Uncontrolled hypertension can lead to stroke & $372(96.6)$ & $13(3.4)$ \\
\hline 7 & $\begin{array}{l}\text { Vision of someone with hypertension is usually } \\
\text { poor }\end{array}$ & $266(69.1)$ & $119(30.9)$ \\
\hline 8 & $\begin{array}{l}\text { Poor management of hypertension can lead to heart } \\
\text { attack }\end{array}$ & $336(87.3)$ & $49(12.7)$ \\
\hline & How to detect hypertension & $\begin{array}{l}\text { YES } \\
\mathbf{N}(\%)\end{array}$ & $\begin{array}{l}\text { NO } \\
\text { N }(\%)\end{array}$ \\
\hline 9 & $\begin{array}{l}\text { Having a health professional measure blood } \\
\text { pressure }\end{array}$ & $322(75.8)$ & $93(24.2)$ \\
\hline & When you start noticing strange feelings in yo & $292(75.8)$ & $93(24.2)$ \\
\hline
\end{tabular}

\section{Table III: Teachers Distribution of Knowledge Regarding Risk Factors}

$\begin{array}{llcc}\text { S/N } & \text { Risk Factors } & \text { YES } & \text { NO } \\ 1 & \text { Foods high in fats } & \mathbf{N}(\mathbf{\%}) & \mathbf{N}(\mathbf{\%}) \\ 2 & \text { Excessive salt consumption } & 252(65.5) & 133(34.5) \\ 3 & \text { Eating too much } & 312(81.0) & 73(19.0) \\ 4 & \text { Low intake of fruits and vegetables } & 95(24.7) & 290(75.3) \\ 5 & \text { Lack of exercises or physical activity } & 245(63.6) & 140(36.4) \\ 6 & \text { Not drinking adequate water } & 292(75.8) & 93(24.2) \\ 7 & \text { Being overweight or obese } & 229(59.5) & 156(40.5) \\ 8 & \text { Having a short stature } & 256(66.5) & 129(33.5) \\ 9 & \text { Having a family history of hypertension } & 62(16.1) & 323(83.9) \\ 10 & \text { Having underlying diseases like diabetes } & 312(81.0) & 73(19.0) \\ 11 & \text { Taking too much alcohol } & 272(70.6) & 113(29.4) \\ & & 284(73.8) & 101(26.2)\end{array}$




\section{Distribution of the Level of Knowledge of Teachers Regarding Hypertension}

Knowledge was computed on a 21-point rating scale with a mean \pm SD of $14.79 \pm 2.298$. The distribution showed that no teacher had poor knowledge regarding hypertension, while 35 (9.1\%) teachers had scores below average and 244 (63.4\%) teachers had scores above average. 106 teachers $(27.5 \%)$ had good knowledge scores.

\section{Teachers' Hypertension Prevention Practices}

The distribution of the teachers' prevention practices showed that only $59(15.3 \%)$ of the teachers did not perform routine blood pressure checks, while $77(20 \%)$ teachers confirmed that they did this very often. Regarding physical activities like walking, swimming and cycling, $159(41.3 \%)$ teachers stated that they practiced this very often and only $28(7.3 \%)$ teachers did not. The distribution of the teachers on the consumption of animal fats showed that only 83 (21.6\%) teachers never ate such, while $112(28.8 \%)$ teachers occasionally ate them and 79 $(20.5 \%)$ very often did. About half of the teachers $(192 ; 49.4 \%)$ stated that they very often avoid tobacco smoking, while only 93 (24.2) stated otherwise. Likewise, 179 (46.5\%) teachers very often limited alcohol consumption, 125 (27.3\%) never did and $43(11.2 \%)$ rarely did. About the consumption of salt, $245(63.6 \%)$ teachers did not practice this prevention behaviour, while only $20(5.2 \%)$ very often did. About a third of the teachers $(136 ; 35.3 \%)$ occasionally consume diets that contain adequate fruits and vegetables. 175 teachers very often maintained a diet low in fat and salt (see Table IV).

\section{Table IV: Distribution of Teachers' Prevention Practices}

\section{$N=$ Not at all, $R=$ Rarely, $O=$ Occasionally, $V O=$ Very Often}

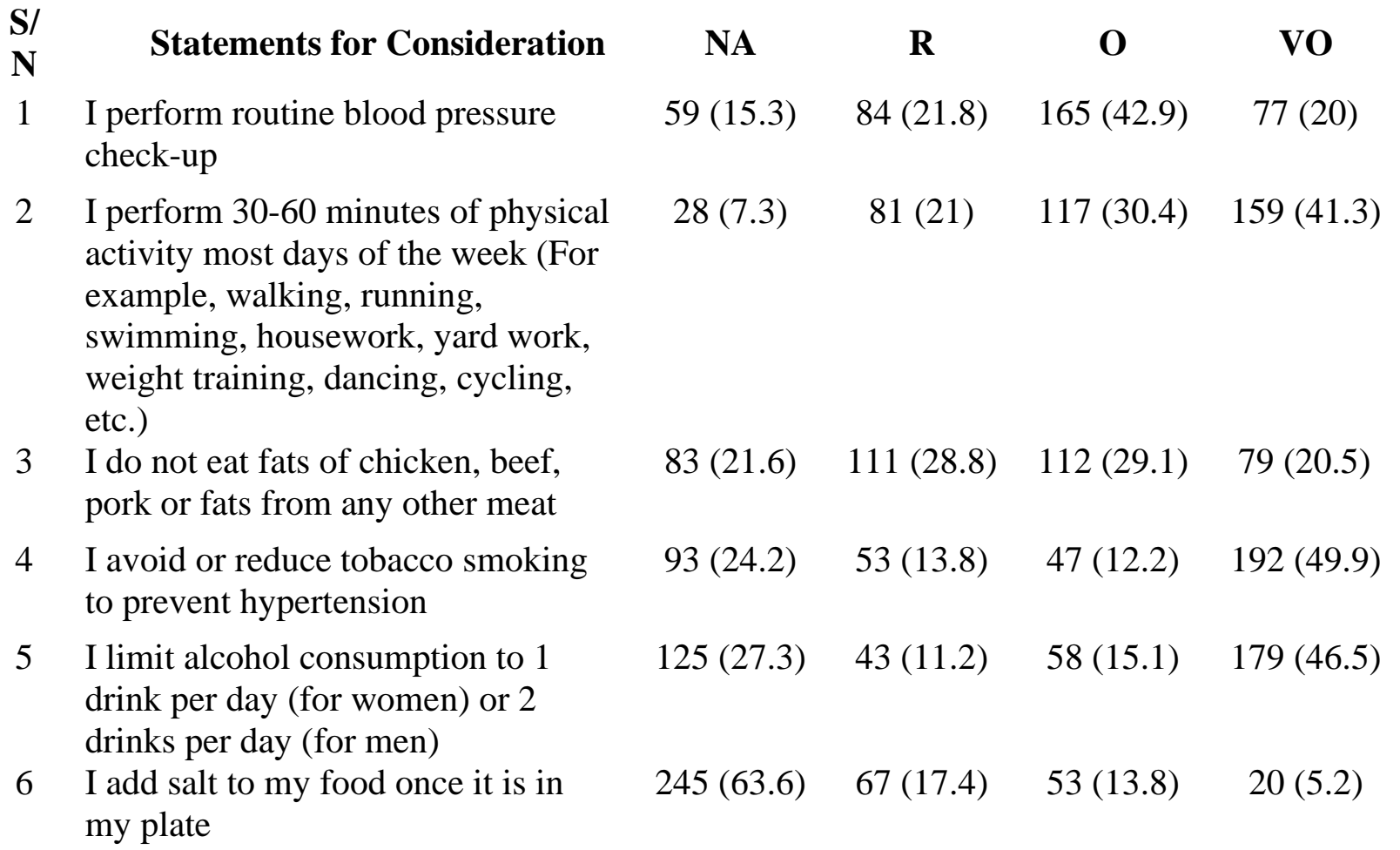




$\begin{array}{llllll}7 & \begin{array}{l}\text { On a daily basis, I consume a diet } \\ \text { that contains adequate fruits and } \\ \text { vegetables }\end{array} & 40(10.4) & 69(17.9) & 136(35.3) & 140(36.4) \\ 8 & \begin{array}{l}\text { I maintain a diet that is low in fat, } \\ \text { low in cholesterol and low in salt }\end{array} & 44(11.4) & 64(16.6) & 102(26.5) & 175(45.5\end{array}$

\section{Level of Prevention Practices of Teachers to Hypertension}

The prevention practices of the teachers were assessed on a 24-point rating scale with a mean \pm SD of $15.34 \pm 4.983$. The distribution showed that only $39(10.1 \%)$ of the teachers had a low level of practice, $172(44.7 \%)$ had a medium level and $174(45.2 \%)$ had a high level.

\section{Test of Hypothesis}

The Pearson Product Correlation analysis was used to test the relationship between the knowledge of teachers regarding hypertension and the prevention practices. There was a statistically significant relationship between knowledge of teachers and the prevention practices $(r=0.199 ; p=0.000)$. The researcher accepts the alternate hypothesis. Regression analysis revealed that the perception was responsible for only $4 \%\left(r^{2}=0.040\right)$ of the variation observed in the practices and measures towards hypertension prevention among the public secondary school teachers.

\section{DISCUSSION}

This study assessed knowledge as a predictor of hypertension prevention among public secondary school teachers in Ogbomoso, Oyo State. The age distribution of the teachers showed that almost half of them were between the ages of 40-49 years and the mean age was $42.64 \pm 7.779$ years. This distribution is similar to the population in a study conducted by Obembe, Osungbade \& Ademokun (2016) and Annadurai (2018). In accordance with the civil service retirement age, none of the teachers was above 60 years of age. The gender distribution showed that there were more females than males across public secondary schools in Ogbomoso. The distribution of the academic qualifications of the teachers indicated that threequarters of the teachers were degree holders and only a small proportion had the National Certificate in Education (NCE). This indicates that there has been a rapid shift from the NCE certification of teachers, at the basic level, to Bachelor's degree.

Majority of the teachers knew that hypertension is caused by a high blood pressure and they were able to affirm the readings on the monitor to diagnose an individual of hypertension. Likewise, the teachers knew that an uncontrolled high blood pressure can lead to stroke/heart attack. Regarding early detection, a high proportion of the teachers confirmed that frequent monitoring of the blood pressure can help in early discovery of hypertension. The teachers were asked about their knowledge of risk factors and the overall response showed that they had moderate knowledge of the factors that can predispose to high blood pressure and eventually hypertension. Consumption of foods high in salts and fats has been identified by the majority of the teachers. The knowledge of these risk factors is one of the most important identified risk factors of hypertension (Martinez-Gomez, Guallar-Castillon, Higueras-Fresnillo, Banegas, Sadarangani \& Rodriguez-Artalejo, 2018; Neelakantan, Koh, Yuan \& van Dam, 2018). One of 
the biological risk factors of hypertension - family history — was correctly identified by over eighty percent of the teachers. This is an important preventive information that influences the behavioural practices towards high blood pressure and hypertension. The study shows that on the grand scale, $41 \%$ of the teachers had a moderate level of knowledge, while only $59 \%$ showed evidence of a high level of knowledge.

Another important risk factor is the lack of physical activities which was confirmed by threequarter of the teachers to be responsible for hypertension. Consistently, studies have suggested a relationship between physical activity and the incidence of hypertension (Brook, Appel, Rubenfire, Ogedegbe, Bisognano \& Elliott, 2013; Chobanian, Bakris, Black, Cushman, Green \& Izzo Jr, 2003). The benefits of physical exercise in reducing blood pressure levels and the risk of cardiovascular conditions have been documented as well as in increasing fitness level, improving body composition and quality of life, and decreasing mortality risk (Williams, B; Mancia, G \& Spiering, 2018; Whelton, PK; Carey, RM \& Aronow, 2018).

There are reportedly strong relationships between behavioural lifestyle factors such as unhealthy diets, physical inactivity, excessive weight gain and the risk of developing hypertension. There was a significant but weak relationship between the knowledge of the teachers and their preventive practices. Knowledge accounted for only $4 \%$ of the variation observed in the preventive practices. This result showed that knowledge was only a minor determinant of the preventive practices that the teachers adopted in their lifestyles.

A large proportion of risk factors associated with hypertension are preventable. As far as the preventive practices are concerned, about two-thirds of the teachers in this study reported that they perform routine blood pressure check-ups. This rate was higher than the rate reported by Oladapo, Salako, Sadiq, Soyinka and Falase (2013). Only a few of the teachers reported about adding salt to their meals after cooking has been done. Regarding the consumption of foods low in fats, vegetables and fruits, the proportion was high but can be improved. This indicates that more education regarding the impact of nutrition needs to be conducted especially among the at-risk groups such as teachers. Poor prevention practices may lead to high risks of hypertension as well as higher chances of other terminal health conditions among teachers. This may adversely affect their productivity and impair their ability to live a normal life as well as deliver a proper education in school. Only $45.2 \%$ of the teachers had a high level of prevention practices.

\section{Implication to Research and Practice}

The findings of this study revealed the teachers present certain risks to psycho-cognitive conditions which can predispose them to hypertension, and thereby suggest an urgent need for a comprehensive health education for teachers. In Nigeria, teachers constitute part of the labour force and it has become a necessity to establish strategies which will improve their health choices. General awareness should be created about the harmful effects of unhealthy diets, lack of physical exercises and extra salt consumption among adults in Nigeria. Therefore, establishing a screening system for early detection of hypertension becomes a prime necessity, along with promoting lifestyle intervention programs focusing on healthy diet and regular physical activity that helps in reducing the overall blood pressure related complications. 


\section{CONCLUSION}

This study highlights knowledge as a predictor of preventive practices relating to hypertension prevention among public secondary school teachers in Ogbomoso North Local Government area. The findings of this study indicate that the level of knowledge and preventive measures of teachers regarding hypertension was moderate. The findings revealed that knowledge has a weak predicting power on preventive measures towards hypertension. This implies that there are other salient factors which may contribute to the practice of hypertension prevention practices among teachers. There is a need to carry out an extensive study to explore these factors. Although the knowledge of the teachers regarding hypertension is moderate, the findings of the study suggest that there are gaps in the knowledge regarding hypertension among teachers in Oyo State, which could influence their behaviours towards prevention. The teachers have an idea of the condition but that is not enough to translate into practice. This study points to a crucial need for comprehensive health education for this group as teachers represent a large and growing segment of the workforce in many countries.

\section{Future Research}

Routine screening for early diagnosis should be conducted for teachers. This will ensure that hypertension is detected early and appropriate management is implemented for affected individuals. A comprehensive awareness of high blood pressure and hypertension should be considered to promote health education especially regarding preventive and risk factors of hypertension. This will have a great impact on the primordial and primary prevention of hypertension in Oyo State. Other longitudinal studies should be conducted to examine the prevalence of high blood pressure among teachers in Ogbomoso and Oyo State at large. Hypertension is a preventable disease and the majority of its risk factors among school teachers are modifiable and preventable. Early diagnosis, preventive behaviour and taking policies can reduce the burden of the disease. Promoting healthy lifestyles and interventions tailored to behavioural modifications related to the risk factors of hypertension is suggested in reducing and controlling the prevalence of hypertension.

\section{REFERENCES}

Adkins H (2006). Getting the message across. Cater Hotelk [Internet]; 196(4447):13. http://search.ebscohost.com/login.aspx?direct=true \&db=buh\&AN=23331140\&site=eho st-live\&scope $=$ site

Annadurai, K. (2018). Awareness and preventive practices related to hypertension among government school teachers in rural Tamil Nadu. Journal of Comprehensive Health, 6(1), 09 - 13. Retrieved from https://www.journalofcomprehensivehealth.co.in/jch/article/view/3

Boateng, D., Wekesah, F., Browne, J. L., Agyemang, C., Agyei-Baffour, P., Aikins, A. D., Smit, H. A., Grobbee, D. E., \& Klipstein-Grobusch, K. (2017). Knowledge and awareness of and perception towards cardiovascular disease risk in sub-Saharan Africa: A systematic review. PloS one, 12(12), e0189264. https://doi.org/10.1371/journal.pone.0189264 
Brook, R. D., Appel, L. J., Rubenfire, M., Ogedegbe, G., Bisognano, J. D., Elliott, W. J., Fuchs, F. D., Hughes, J. W., Lackland, D. T., Staffileno, B. A., Townsend, R. R., Rajagopalan, S., \& American Heart Association Professional Education Committee of the Council for High Blood Pressure Research, Council on Cardiovascular and Stroke Nursing, Council on Epidemiology and Prevention, and Council on Nutrition, Physical Activity (2013). Beyond medications and diet: alternative approaches to lowering blood pressure: a scientific statement from the american heart association. Hypertension (Dallas, Tex. : 1979), 61(6), 1360-1383. https://doi.org/10.1161/HYP.0b013e318293645f

Chobanian, A. V., Bakris, G. L., Black, H. R., Cushman, W. C., Green, L. A., Izzo, J. L., Jr, Jones, D. W., Materson, B. J., Oparil, S., Wright, J. T., Jr, Roccella, E. J., Joint National Committee on Prevention, Detection, Evaluation, and Treatment of High Blood Pressure. National Heart, Lung, and Blood Institute, \& National High Blood Pressure Education Program Coordinating Committee (2003). Seventh report of the Joint National Committee on Prevention, Detection, Evaluation, and Treatment of High Blood Pressure. Hypertension (Dallas, Tex. : 1979), 42(6), 1206-1252. https://doi.org/10.1161/01.HYP.0000107251.49515.c2

Chruściel, Piotr \& Stemplewska, Paulina \& Stemplewski, Adam \& Wattad, Mohamad \& Bielecka-Dąbrowa, Agata \& Maciejewski, Marek \& Penson, Peter \& Bartlomiejczyk, Marcin \& Banach, Maciej. (2019). Associations between the lipid profile and the development of hypertension in young individuals - the preliminary study. Archives of Medical Science. 16. 10.5114/aoms.2019.86197.

Dzau, V. J., \& Balatbat, C. A. (2019). Future of Hypertension. Hypertension (Dallas, Tex. : 1979), 74(3), 450-457. https://doi.org/10.1161/HYPERTENSIONAHA.119.13437

Eman Anwar Dia, (2020). Diversity and Equality in Health. Retrieved from https://diversityhealthcare.imedpub.com/hypertension-2020-marketanalysis.php?aid=26209

Lemogoum D. (2014). Challenge for hypertension prevention and control worldwide: the time for action. J Clin Hypertens; 16:554-6.

Martinez-Gomez D, Guallar-Castillon P, Higueras-Fresnillo S, Banegas JR, Sadarangani KP, Rodriguez-Artalejo F. (2018). A healthy lifestyle attenuates the effect of polypharmacy on total and cardiovascular mortality: A national prospective cohort study. Sci Rep;8:12615. [PMC free article] [PubMed] [Google Scholar]

Mohan, V., Mathur, P., Deepa, R., Deepa, M., Shukla, D. K., Menon, G. R., Anand, K., Desai, N. G., Joshi, P. P., Mahanta, J., Thankappan, K. R., \& Shah, B. (2008). Urban rural differences in prevalence of self-reported diabetes in India--the WHO-ICMR Indian NCD risk factor surveillance. Diabetes research and clinical practice, 80(1), 159-168. https://doi.org/10.1016/j.diabres.2007.11.018

Neelakantan N, Koh WP, Yuan JM, van Dam RM. (2018). Diet- quality indexes are associated with a lower risk of cardiovascular, respiratory, and all-cause mortality among Chinese adults. J Nutr;148:1323-32. [PMC free article] [PubMed] [Google Scholar]

Obembe, T. A., Osungbade, K. O., \& Ademokun, O. M. (2016). Awareness and knowledge of National School Health Policy and School Health Programme among public secondary school teachers in Ibadan metropolis. Nigerian medical journal: journal of the Nigeria Medical Association, 57(4), 217-225. https://doi.org/10.4103/0300$\underline{1652.188341}$ 
Oladapo O.O, Salako L, Sadiq L, Soyinka K and Falase A.O. (2013). Knowledge of Hypertension and other Risk Factors for Heart Disease among Yoruba Rural Southwestern Nigerian Population. British Journal of Medicine \& Medical Research;3: 993-1003.

Olamoyegun MA, Oluyombo R, Iwuala SO, Asaolu SO. (2016). Epidemiology and patterns of hypertension in semi-urban communities, south-western Nigeria. Cardiovasc $J$ Afr. 23;27(6):356-360. https://doi: 10.5830/CVJA-2016-037.

Sarah Jane Monica, Sheila John and Madhanagopal R (2017). Lifestyle Determinants of Hypertension among Female School Teachers; International J. of Life Sciences, 5 (4): 697-702.

Singh M \& Sing G (2006) Assessment of mental health status of middle aged female school teachers of Varanasi city. International Journal of Health. 5(1): 6-18.

Whelton, P. K., Carey, R. M., Aronow, W. S., Casey, D. E., Jr, Collins, K. J., Dennison Himmelfarb, C., DePalma, S. M., Gidding, S., Jamerson, K. A., Jones, D. W., MacLaughlin, E. J., Muntner, P., Ovbiagele, B., Smith, S. C., Jr, Spencer, C. C., Stafford, R. S., Taler, S. J., Thomas, R. J., Williams, K. A., Sr, Williamson, J. D., ... Wright, J. T., Jr (2018). 2017 ACC/AHA/AAPA/ABC/ACPM/AGS/APhA/ASH/ASPC/NMA/PCNA Guideline for the Prevention, Detection, Evaluation, and Management of High Blood Pressure in Adults: Executive Summary: A Report of the American College of Cardiology/American Heart Association Task Force on Clinical Practice Guidelines. Hypertension (Dallas, Tex. : 1979), 71(6), 1269-1324. https://doi.org/10.1161/HYP.0000000000000066

Williams, B, Mancia, G, Spiering, W. (2018). ESC/ESH guidelines for the management of arterial hypertension. Eur Heart J;39:3021-3104.

World Health Organization (2019). Hypertension. Retrieved from: https://www.who.int/news-room/fact-sheets/detail/hypertension 